\title{
REPRESENTASI BERITA PENISTAAAN AGAMA DALAM MEDIA MASSA DI INDONESIA
}

\author{
Muhammad Fahmi \\ Dosen Komunikasi dan Penyiaran Islam IAIN Surakarta \\ fahmielhalimy@gmail.com
}

\begin{abstract}
This paper aims to analyze the representation of mass media in Surakarta, they are Solopos and Joglosemar, in the case of the religion blasphemy made by Basuki Cahaya Purnama (Ahok). This study used a method of critical discourse analysis of Theo van Leuwen that focused on how the actors are being included and excluded on the media news. The findings demonstrated that: (1) Solo Pos was in Ahok's side. In this case, Ahok is to be excluded (omitted and blurred from the narrative text) when it comes to negative information regarding him and also is to be included (made clear) if it is about the positive information regarding Ahok. (2) Joglosemar also demonstrated in supportting Ahok. Joglosemar uses exclusion and passivation techniques. The use of these two techniques is done as long as giving "profit" to Ahok. (3) There are three factors that influence framing of news, construction and media representation that make the media are likely supporting Ahok, they are: 1). Surakarta as the area factor for the basis of the Nationalist party, 2) Joko Widodo (Jokowi) as the current president of Indonesia, 3) the owners of media. These factors ultimately affected on the news regarding the blasphemy case of Ahok in which the media tended to defend Ahok.
\end{abstract}

Keywords: $\quad$ representation, religion, media, discourse

\begin{abstract}
Abstrak
Artikel ini ingin melihat bagaimana representasi media massa di Surakarta, yaitu Solopos dan Joglosemar, pada kasus peninstaan Agama oleh Basuki Cahaya Purnama (Ahok). Metode yang digunakan adalah analisis wacana kritis Theo van Leuwen yang fokus pada bagaimana para aktor di-inklusi dan eksklusi dalam berita media. Hasil penelitian ini menjelaskan bahwa: (1) Solo Pos berpihak pada Ahok. Ahok di-eksklusi (dihilangkan, diburamkan dari teks naratif) ketika menyangkut informasi negatif dan sebaliknya, diinklusi (dibuat terang) jika informasi berita positif untuk Ahok. (2) Joglosemar terlihat juga mendukung Ahok. Joglosemar menggunakan teknik eksklusi dan passivasi. Penggunaan kedua teknik ini dilakukan selama memberikan "keuntungan" kepada Ahok. (3) ada tiga faktor yang mempengaruhi framing, konstruksi dan representasi media yang membuat media terlihat mendukung Ahok, yaitu: 1). Faktor Surakarta sebagai basis partai nasionalis, Faktor Joko Widodo (Jokowi), Faktor pemilik media. Faktor-faktor ini pada akhirnya berdampak pada berita yang terkait dengan kasus penodaan agama yang dilakukan oleh Ahok dimana media cenderung membela Ahok.
\end{abstract}

Kata Kunci: representasi, agama, media, wacana 


\section{Pendahuluan}

Penistaan agama nampaknya masih menjadi isu besar di Indonesia. Hal ini mengingat bangsa Indonesia dikenal sebagai bangsa religius (Intan, 2006:156). Lebih-lebih lagi penistaan terhadap agama Islam, sebagai agama mayoritas (Rooij, 2015:195), pasti akan memantik reaksi yang bersifat massif. Terbukti, kasus pelecehan agama oleh Basuki Cahaya Purnama (Ahok) menimbulkan arus deras gelombang unjuk rasa di sanasini. Contoh yang paling nyata adalah aksi Bela Islam pada tanggal 02 Desember 2016 (pupuler disebut dengan Aksi 212) yang fenomenal, diikuti oleh jutaan umat Islam di Indonesia (http://www.republika. co.id/berita/kolom/fokust). Mereka terpanggil untuk ikut aksi di Jakarta karena tergerak oleh perasaan untuk membela agama yang mereka yakini.

Aksi-aksi menjadi semacam perlawanan simbolik umat Islam terhadap Ahok yang dianggap telah melecehkan agama mereka. Gerakan simbolik ini terbukti efektif mendeterminasi kebijakan konkrit terhadap Ahok. Gubernur DKI tersebut diajukan ke persidangan dan untuk kemudian dihukum atas tindakan pelecehan agama yang dilakukannya. Bukan itu saja, Ahok juga harus rela melepas kursi gubernurnya tatkala keputusan pengadilan yang menyatakan ia bersalah pasca dicabutnya memori banding oleh keluarganya meski sebelumnya sudah dikirim ke pengadilan. Tambahan lagi, keributan dari kasus pelecehan agama ini juga mempengaruhi hasil Pilkada DKI.

Pasangan petahana calon gubernur DKI periode 2017-2022, Ahok-Djarot Saiful Hidayat dikalahkan oleh kompetitor mereka: Anies Baswedan-Sandiaga Uno, pada pemilihan putaran kedua Pilkada DKI yang lalu. Ironisnya, keputusan hukuman pidana Ahok oleh hakim pengadilan terjadi tepat setelah 1 hari pasca ditetapkannya keputusan Komisi Pemilihan Umum(KPU) Propinsi Daerah Khusus Ibukota Jakarta, yang memenangkan lawan mereka: Anis dan Sandiaga ibarat pepatah, sudah jatuh tertimpa tangga pula, begitu tepatnya untuk menggambarkan 
nasib Ahok. Tidak hanya kalah pada Pilkada, tapi Ahok juga kalah pada persidangan dan harus mendekam di penjara sebagai narapidana.

Kasus penistaan agama telah menjegal Ahok dari panggung politik dan singgasana kekuasaan di Indonesia. Ini membuktikan bahwa isu-isu Sara (Suku Agama Ras Antar Golongan) masih sangat sensitif di Indonesia. Ini juga membuktikan bahwa kekuatan simbolik (symbolic power) yang dimiliki agama tidak bisa diremehkan. Sebagaimana dinyatakan oleh Pierre Bourdieu (1991:11), bahwa model-model simbolik adalah modal yang tertinggi, modal yang paling kuat, bahkan mengalahkan modal modal lain, seperti modal ekonomi, modal sosial dan modal budaya. Berkali-kali dalam sejarah Indonesia, agama menjadi kekuatan simbolik. Sejak dari perang merebut dan mempertahankan kemerdekaan, bahkan perang melawan komunisme, menunjukkan agama menjadi kekuatan simbolik yang mampu mengintegrasikan umat dalam barisan perlawanan, baik pada penjajahan maupun komunisme.

Kajian ini ingin melihat lebih dalam bagaimana kasus penistaan agama ini direpresentasikan dalam media massa di Surakarta. Sebagai kota yang diberi gelar kota sumbu pendek, basis kelompok Islam garis keras, kota tempat dimana dulu Abdullah Ba'asir mengajar di pesantren Ngruki, tentu menarik untuk melihat bagaimana media lokal merepresentasikan kasus penistaan agama yang dilakukan oleh Ahok. Apakah berita media merefleksikan konteks sosial Surakarta seperti yang digambarkan di atas, atau media melakukan kontestasi, dengan merepresentasikan kasus tersebut secara berbeda.

\section{Permasalahan}

Dari latar belakang di atas fokus permasalahan adalah: (1) bagaimana representasikan berita penistaan agama dalam media massa di Indonesia? (2) Faktor-faktor apa yang mempengaruhi representasi media tersebut? 


\section{Tinjauan Pustaka}

C.L. Fenton, dan M.A. Fenton (2016:181) melihat bahwa kasus Ahok sebagai bentuk fanatisme dan Intoleransi agama di Indonesia. Keduanya merupakan faktor yang berkontribusi dalam konflik sosial dan politik termasuk manifestasi kekerasan teroris. Sementara kebebasan beragama diabadikan dalam Konstitusi Indonesia, praktik sosial dan peraturan pemerintah tidak memenuhi jaminan hukum konstitusional dan internasional, yang memungkinkan bias yang terlembaga dalam perlakuan terhadap minoritas agama. Bias semacam itu menghambat transisi Indonesia menuju demokrasi pluralistik yang berfungsi penuh dan mengorbankan cita-cita demokrasi dari kebebasan pribadi dan kebebasan berekspresi untuk tujuan yang dinyatakan dari kerukunan beragama dan sosial. Kasus Ahok secara tepat menegaskan hal itu. Dasar-dasar konstitusi kebebasan beragama, Undang-undang Penodaan Agama Indonesia dan mempertimbangkan sejarah dan ajaran Pancasila yang mendikte kepercayaan kepada Tuhan sebagai prinsip pertama ideologi negara. Kegagalan negara Indonesia untuk mengakui legitimasi posisi teologis alternatif merupakan hambatan utama bagi Indonesia untuk mengakui cita-cita tertinggi, yang diabadikan dalam semboyan nasional, persatuan dalam keberagaman.

Senada dengan Fenton bersaudara, (dalam Subhan, 2007:519) dalam artikelnya membahas peraturan negara yang terkait dengan definisi agama dan kebebasan beragama, yang memang kontroversial. Sebagian orang memahaminya sebagai bagian dari upaya yang lebih besar untuk menciptakan kehidupan religius yang harmonis dan damai, sementara yang lain memahaminya sebagai intervensi dan pelanggaran kebebasan beragama. Kelompok-kelompok yang disebut terakhir mengajukan peninjauan kembali kepada UU No 1/PNPS/1965. Meskipun Mahkamah Konstitusi Indonesia menolaknya, setidaknya itu menjelaskan pemberantasan dalam pandangan masyarakat tentang seberapa 
jauh negara berwenang untuk mengatur kehidupan beragama. Konstitusi Indonesia secara formal mengakui bahwa kebebasan beragama merupakan bagian integral dari kehidupan sipil.

Berbeda dengan Fenton dan Subhan di atas yang memfokuskan penelitiannya pada aspek konstitusi Indonesia yang dianggapnya bias, artikel saya memokuskan kajian pada berita media massa. Kajian ini akan memperlihatkan bagaimana representasi agama, terutama dalam kaitannya dengan kasus Ahok, tidak bisa dilepaskan dari bias media. Dalam pandangan umum, media dianggap sebagai institusi netral yang menyampaikan informasi kepada khalayak secara apa adanya. Padahal, media justru memiliki kepentingan untuk memproduksi makna-makna tertentu sesuai dengan keinginan dan tujuan media. Khalayak penting untuk menyadari bahwa apa yang disampaikan oleh media bukanlah realitas sebenarnya tetapi realitas yang sudah melewati sejumlah proses seperti: Penyuntingan, edit dan penyesuaian dengan agenda-seting serta kepentingan media (Burton, 2008: 86).

Institusi-institusi media sosial sering dianggap bersikap netral dalam menyediakan ruang bagi wacana publik. Fairclough menunjukkan kesalahan dari asumsi tersebut, dan menggambarkan mediatisasi dan konstruksi discourse oleh media justru dilakukan demi agenda setting, kepentingan dan ideologi pelaku media. Hal itu, berarti discourse media sosial sangat tendensius dan subjektif. Padahal, publik kerap melihat bahwa media sosial bersifat objektif dan netral. Akibatnya, discourse media ditelan mentah-mentah begitu saja. Para ahli wacana meyakini bahwa ilmu pengetahuan, termasuk di dalamnya discourse media, secara inheren merupakan bagian dan dipengaruhi oleh struktur sosial dan diproduksi dalam interaksi sosial (Fairclough, 1995: 65; Scott, 1988: 35; Udasmoro, 2009: 1).

Althusser (1984:17) mengkritik media yang disebutnya telah menjadi aparat ideologis (ideological state apparatus). Media menjadi 
"corong" kepentingan dan ideologi pelaku media. Inilah yang oleh Berger dan Luckmann (1966: 23) disebut dengan realitas yang sudah dikontruksikan (constructed reality). Artinya, media melakukan politik pemaknaan, memproduksi konsensus ataupun disensus, menyebarkan nilai-nilai, ideologi, interes, misi, tujuan dan kepentingan media (Barker, 2004: 2). Oleh karena itu, menurut Hall penting untuk melihat bagaimana sistem representasi bekerja dalam sebuah media. Hal ini mengingat karena seluruh makna akan ditentukan oleh representasi tersebut.Karena itu, dalam kajian budaya dan media, istilah representasi dimaknai sebagai production of the meaning of the concepts in our mind through language (Hall, 2003:15).

\section{Metodelogi Penelitian}

Kajian ini menggunakan metode penelitian kualitatif dengan menggunakan pendekatan analisis wacana kritis (Critical Discourse Analysis) yaitu analisis wacana dari Theo van Leeuwen yang memusatkan pada bagaimana aktor atau subjek tertentu direpresentasikan.

Pada penelitian ini, analisis fokus pada bagaimana para aktor atau subjek yang terkait dengan kasus penistaan agama yang menyangkut kasus Ahok ditampilkan (inklusi) atau dikeluarkan (eksklusi) dalam sebuah pemberitaan dalam media massa di Surakarta: Solopos dan Joglo-Semar.

Tabel 1. Teknik Eksklusi dan Inklusi yang dimodifikasi (Khuriyati, 2013: 27)

\begin{tabular}{ll}
\hline Teknik & \multicolumn{1}{c}{ Yang ingin dilihat } \\
\hline & $\begin{array}{l}\text { a. Apakah ada penghilangan aktor dalam pemberitaan? } \\
\text { (Pasivasi). }\end{array}$ \\
b. Apakah ada upaya media untuk mengedepankan aktor \\
Eksklusi & $\begin{array}{l}\text { certentu dan menghilangkan aktor lain? (Nominalisasi) } \\
\text { cagaimana strategi yang dilakukan untuk menyembunyikan } \\
\text { atau menghilangkan aktor sosial tersebut? Apakah subjek } \\
\text { atau aktor dihilangkan dengan memakai anak kalimat? } \\
\text { (Penggantian Anak Kalimat) }\end{array}$ \\
\hline
\end{tabular}




\begin{tabular}{cl}
\hline Teknik & \multicolumn{1}{c}{ Yang ingin dilihat } \\
\hline & a. Bagaimana para aktor ditampilkan dalam teks berita secara \\
& berbeda? (Diferensiasi/indeferensiasi) \\
& b. Apakah suatu peristiwa atau aktor sosial ditampilkan dengan \\
& memberi petunjuk yang konkrit? (Objektivasi/Abstraksi) \\
Inklusi & c. Apakah aktor ditampilkan apa adanya atau media \\
& mengkategorisasi aktor tersebut? (Nominasi/Kategorisasi) \\
& d. Apakah aktor digambarkan dengan identitas buruk atau \\
& sterotype tertentu? (Nominasi/Identifikasi) \\
& e. Apakah peristiwa atau aktor ditampilkan dengan jelas atau \\
& tidak (anonim)? (Determinasi/Indeterminasi) \\
\hline
\end{tabular}

\section{Hasil Penelitian}

Tabel 2. Temuan Penelitian

\begin{tabular}{|c|c|c|c|}
\hline No & Temuan & Indikator & Keterangan \\
\hline 1 & $\begin{array}{l}\text { Solopos berpihak } \\
\text { ke Ahok }\end{array}$ & $\begin{array}{l}\text { Artikel yang berjudul: Jaksa } \\
\text { Agung Sebut Ahok Tak Terbukti } \\
\text { Nistakan Agama. } \\
\text { Ahok dieksklusi jika } \\
\text { menyangkut informasi negatif } \\
\text { dan diinklusi jika sebaliknya; } \\
\text { berita bersifat positif bagi } \\
\text { Ahok }\end{array}$ & $\begin{array}{l}\text { Inklusi: "Jaksa Agung HM Prasetyo } \\
\text { menegaskan Basuki Tjahaja } \\
\text { Purnama atau Ahok tidak terbukti } \\
\text { melakukan tindak penistaan } \\
\text { agama... } \\
\text { Eksklusi: "Itu bukan penistaan } \\
\text { agama, yang terbukti bukan } \\
\text { penistaan agama," kata Prasetyo } \\
\text { di Jakarta, Jumat (21/4/2017). } \\
\text { Padahal, sebelumnya, jaksa } \\
\text { penuntut umum menggunakan } \\
\text { dakwaan alternatif, yaitu dengan } \\
\text { Pasal 156A KUHP dan Pasal } 156 \\
\text { KUHP. }\end{array}$ \\
\hline 2 & $\begin{array}{l}\text { Solopos terlihat } \\
\text { berusaha untuk } \\
\text { cover both side, tapi } \\
\text { masih terlihat } \\
\text { berpihak ke Ahok }\end{array}$ & $\begin{array}{l}\text { Artikel yang berjudul: Ahok } \\
\text { Divonis } 2 \text { Tahun Penjara. Ahok } \\
\text { diinklusi-absraksi. }\end{array}$ & $\begin{array}{l}\text { Inklusi-abstraksi pada: ..."Hakim } \\
\text { menilai unsur dengan sengaja dalam } \\
\text { pidato Ahok itu telah terpenuhi". } \\
\text { Teks berita tidak menjelaskan unsur } \\
\text { penodaan agama. }\end{array}$ \\
\hline \multirow[t]{2}{*}{3} & $\begin{array}{l}\text { Judul artikel } \\
\text { Solopos } \\
\text { tendensius }\end{array}$ & $\begin{array}{l}\text { Artikel yang berjudul : } \\
\text { 1. Ahok Tersangka: Tak Perlu } \\
\text { Lagi Ada Demo" }\end{array}$ & $\begin{array}{l}\text { Sub Judul "Ahok tersangka" dibuat } \\
\text { kecil sementara "Tak Perlu Lagi } \\
\text { Ada Demo" dibuat dengan huruf } \\
\text { yang jauh lebih besar. }\end{array}$ \\
\hline & & 2.Kasus Ahok Supercepat & $\begin{array}{l}\text { Judul pakai huruf capital dan pond } \\
\text { besar serta menjadi headline berita } \\
\text { Solopos tanggal } 2 \text { Desember } 2017 \text {. } \\
\text { Mendampingi artikel yang berjudul } \\
\text { Ribuan Warga Soloraya Ikut 212, yang } \\
\text { dibuat kecil untuk mengesankan } \\
\text { cover both side. }\end{array}$ \\
\hline
\end{tabular}




\begin{tabular}{|c|c|c|c|}
\hline No & Temuan & Indikator & Keterangan \\
\hline 4. & $\begin{array}{l}\text { Joglosemar } \\
\text { terlihat berpihak } \\
\text { ke Ahok }\end{array}$ & $\begin{array}{l}\text { Artikel: Ini Dia Pelajaran dari } \\
\text { Kasus Ahok }\end{array}$ & $\begin{array}{l}\text { Pada artikel ini dijelaskan "Usai } \\
\text { mengucapkan itu, warga tertawa- } \\
\text { tawa. Tidak ada yang janggal atas } \\
\text { ucapan Ahok tersebut. Warga Pulau } \\
\text { Pramuka tidak menganggap ucapan } \\
\text { Ahok itu menistakan agama. } \\
\text { Terlebih, Ahok memang dikenal } \\
\text { sebagai pejabat yang ceplas-ceplos } \\
\text { ngomongnya. }\end{array}$ \\
\hline & Joglosemar & $\begin{array}{l}\text { Artikel: Tersangka Kasus } \\
\text { Penistaan Agama, Ini Status } \\
\text { Ahok di Pilgub DKI Jakarta. }\end{array}$ & $\begin{array}{l}\text { Ada eksklusi pasivasi. Pada } \\
\text { kalimat ..."meskipun tak bulat } \\
\text { namun didominasi pendapat yang } \\
\text { menyatakan perkara ini harus } \\
\text { diselesaikan di peradilan terbuka. } \\
\text { Konsekuensinya, penyelidikan } \\
\text { ini akan ditingkatkan ke tahap } \\
\text { penyidikan," }\end{array}$ \\
\hline
\end{tabular}

Dalam kasus penistaan agama oleh Ahok, media yang selama ini diasumsikan netral, justru terindikasi berpihak kepada kubu Ahok. Melalui analisis wacana Theo van Leeuwen (2008:1), terlihat bagaimana media-media di Surakarta, Solopos dan Joglosemar, melalui strategi eksklusi dan inklusi, melakukan pembelaan tersebut. Pembelaan itu bisa berwujud menghilangkan aktor atau membuat kabur kesalahan-kesalahan yang dinisbahkan kepada yang bersangkutan, dengan tujuan untuk mengalihkan fokus dan perhatian, menggiring opini publik untuk setidaktidaknya bisa menerima atau sekedar memaklumi "kesilapan" Ahok. Disinilah terbukti tesis kalangan neo-Marxis yang memandang media sebagai "aparat ideologi" (ideological state apparatus) yang mempunyai target operasi untuk merubah kesadaran khalayak (Althusser dan Louis, 2014:1). Inilah yang disebut oleh Anthony Gramscy sebagai hegemoni (Gramsci, 2010), sebuah dominasi intelektual terhadap khalayak sebagai, meminjam istilah Walter Lippmann, manufacturing consent, penggiringan opini public (Herman, 2002:1).

Pertanyaan kemudian adalah mengapa media-media di Surakarta bersifat demikian? Mengapa media-media yang jauh dari ibukota tersebut terkesan membela Ahok? Padahal, Ahok bukanlah orang Solo atau pernah 
bertugas di kota budaya ini? Ahok juga bukan berasal dari etnis mayoritas di wilayah ini: suku jawa, Ahok beretnis Tionghoa. Setidaknya, ada berbagai faktor di bawah ini yang bisa menjawab pertanyaan-pertanyaan tersebut:

Pertama: Solo sebagai basis partai nasionalis. Secara tradisional, partai-partai nasionalis, bukan partai Islam, selalu mendominasi perpolitikan di wilayah Surakarta. Jika pada zaman Orde lama, PKI bahkan pernah berjaya di kota batik ini (Benedict 2009:1), maka sejak Orde baru sampai dengan Orde reformasi hingga sekarang ini kejayaan selalu berada di bawah PDIP (Partai Demokrasi Indonesia, sejak dipimpin Megawati Soekarno Puteri berubah nama menjadi Partai Demokrasi Indonesia Perjuangan). Bahkan, pada Pemilu 2014 yang lalu, partai berlambang banteng ini selalu mendominasi di parlemen Kota Surakarta, dengan kemenangan lebih dari 50\% (Romli, 2004:1). Ini berarti, setiap kebijakan apapun yang menyangkut Surakarta atau Solo dapat ditentukan oleh satu partai saja yaitu PDIP.

Mengingat posisi penting ini, maka tak mungkin media-media di Surakarta abai kepada partai dominan tersebut. Meski Ahok selalu bilang bahwa ia bukan kader PDIP, tapi dalam berbagai kesempatan Ahok selalu mengatakan bahwa dirinya sebagai "orang Megawati", ketua Partai umum PDIP (https://www.merdeka.com/jakarta/). Apalagi, dalam pilkada DKI, Ahok dipasangkan dengan petahana wakil gubernur, Djarot Saiful Hidayat, kader dan pengurus pusat PDIP. Hal ini makin membuat Ahok untuk dilihat sebagai representasi PDIP. Dengan demikian, tidak heran media-media di Surakarta terkesan membela Ahok karena ia dilihat sebagai "orang PDIP" juga.

Dalam studi media, ada pandangan kuat yang meyakini bahwa ada kaitan antara isi media dengan kelompok yang berkuasa. Ada relasi discourse media dengan kekuasaan (van Dijk, 2008:1). Dalam hal ini, kekuasaan politik PDIP, sebagai mayoritas, begitu dominan di wilayah 
ini. Pun demikian halnya dengan kasus Ahok, dalam atmosfer kekuasaan politik demikian, adalah suatu "tindakan bodoh" jika media tidak mereprsentasikan kepentingan partai berkuasa tersebut, sebab dapat dikatakan PDIP sebagai market sekaligus resources media-media di Surakarta.

Kedua, faktor Jokowi. Fakta menunjukkan bahwa Ahok atau Basuki Tjahaja Purnama adalah wakil Joko Widodo (Jokowi) sewaktu mantan walikota Surakarta tersebut menjadi gubernur DKI. Semua orang tentu tahu bagaimana populernya Jokowi di kalangan media-media. Bahkan, Jokowi sering disebut sebagai "media darling" (Ajidarma, 2016:20). Hubungan Ahok dan Jokowi yang relatif baik selama ini mau tidak mau akan membuat orang melihat Ahok sebagai "orang Jokowi". Dan hal itu tentu akan mempengaruhi sikap media terhadap Ahok. Citra sebagai "orang Jokowi" tentu akan menimbulkan simpati media terhadap Ahok. Hal tersebut terlihat jelas tatkala kita melihat bagaimana media-media di Surakarta merepresentasikan kasus pelecehan agama oleh Ahok, dalam narasi dan wacana yang relatif lebih berempati dan tendensius membela Ahok.

Ketiga, faktor pemilik media. Bukan sebuah kebetulan pemilik media-media di Surakarta berlatar belakang pengusaha: Sukamdani Sahid Gitosardjono, owner Solopos, sebagai pengusaha bisnis media dan perhotelan dan S. Haryadi, pemilik Joglosemar, sebagai pengusaha per bukuan. Latar belakang sebagai pengusaha memiliki peran signifikan dalam membentuk, menentukan dan merepresentasikan isi media. Secara ekonomi politik, Vincent Moskow melihat bagaimana isi media sangat dipengaruhi oleh siapa yang memiliki dan mengontrol media (Mosco, 1998:23).

Dalam perspektif ini, posisi owner, pemilik media, adalah posisi kunci dan penting dan karena itu sangat menentukan framing, konstruksi dan representasi media (Juni wati, 2016:11). Di Indonesia, media sering dilihat sebagai personifikasi pemilik media. Tempo misalnya, dilihat 
sebagai personifikasi Gunawan Muhammad. Sementara, Kompas personifikasi dari Jacob Utama, Metro TV personifikasi dari Surya Paloh, TV One Abu Rizak Bakri, sedangkan RCTI dan MMC group sebagai representasi dari Hari Tanoesoedibjo. Dengan demikian, media-media di Indonesia tak bisa dilepaskan dari personifikasi pemiliknya (Krishna, 2010:121).

Dengan demikian Solopos, dengan media jaringan ekonomi bisnisnya, bisa dilihat sebagai personifikasi dari Sukamdani Sahid Gitosardjono, begitu juga Joglosemar, personifikasi dari S. Haryadi, sebagai pemilik kedua media tersebut. Memang, tidak ada satu pun catatan yang mencolok tentang afiliasi politik kedua pemilik media ini. Namun, untuk Solopos perlu dicatat di situ ada saham Ir. Ciputra, taipan riel estate, yang beretnis sama dengan Ahok: etnis Tionghoa. Sementara, pemilik Joglosemar, S. Haryadi, sebagai pengusaha tentunya tidak bisa melepaskan diri dari jaringan pengusaha WNI keturunan yang mendominasi perekonomian baik daerah maupun nasional.

Faktor-faktor ini pada akhirnya memiliki pengaruh pada bagaimana media memframing, mengkonstruksi dan merepresentasikan berita-berita yang terkait dengan kasus pelecehan agama yang dilakukan oleh Ahok. Media-media tersebut tentu tidak bisa "telanjang" membela Ahok, karena di samping terikat pada konvensi pers yang mengatur tentang cover board sides, yang mengamanahkan media harus berimbang dan proposional (Sudibyo, 2001:28). Pembelaan terang-terangan akan menjadi bumerang bagi media yaitu munculnya resistensi kalangan Islam simbolik yang cukup signifikan dan ekspresif di wilayah Solo Raya ini.

Dengan menggunakan strategi wacana yang halus, pembelaan menjadi tidak kentara, sehinggah publik menjadi menjadi tidak sadar bahwa mereka sedang digiring pada pemahaman tertentu yang dikehendaki media. Seperti kata Noah Chomsky, publik menjadi "ignorant herds" atau kawanan ternak yang sedang digiring kesadarannya. Inilah yang disebut oleh Walter 
Lippmann, manufacturing consent, penggiringan opini publik, sebagai rekayasa media untuk mengiring konsensus public (Edward, 2011:11).

\section{Islam dan Berita Penistaan Agama}

Ummat Islam terlihat berbeda dalam menyikapi kasus Ahok, ini, seperti yang dijelaskan dalam quran surat Al-Maidah ayat 51:

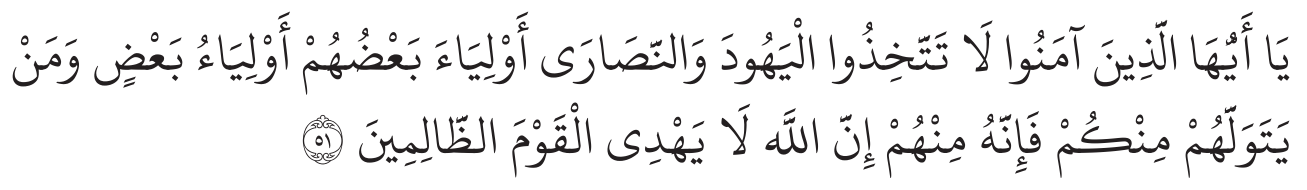

Artinya: Hai orang-orang yang beriman, janganlah kamu mengambil orangorang Yahudi dan Nasrani menjadi auliya bagimu; sebahagian mereka adalah auliya bagi sebahagian yang lain. Barang siapa di antara kamu mengambil mereka menjadi auliya, maka sesungguhnya orang itu termasuk golongan mereka. Sesungguhnya Allah tidak memberi petunjuk kepada orang-orang yang lalim."(QS. Al-Maidah: 51).

Satu gelolongan berpendapat bahwa kata tersebut bermakna "pemimpin" sedangkan yang lain berpendapat bahwa kata tersebut tidak harus bermakna pemimpin: bisa bermakna "teman dekat". Jadi, pada pendapat pertama berlaku "Janganlah kamu mengangkat pemimpin dari golongan selain Islam". Sedangkan pada pendapat yang kedua "janganlah kamu mengambil teman akrab selain dari orang Islam". Meski sekilas tidak ada perbedaan yang sangat mencolok antara kata pemimpin dan teman, karena jika mengangkat pemimpin selain orang Islam saja tidak dibolehkan maka apalagi dengan mengambil teman akrab selain orang Islam. Maka, arti kedua (teman akrab) justru memperkuat arti pertama (pempimpin). Bahkan, makna kedua mengkomplementir makna pertama. Jadi, sebenarnya tidak ada kontradiksi antara kedua makna tersebut, karena keduanya saling melengkapi.

Akan tetapi, dalam konteks politik, pilihan arti "aulia" pada makna "pemimpin" dan "teman akrab" memilliki konsekwensi politis yang signifikan jika dikaitkan dengan Isu Pilkada Daerah Khusus Ibu 
Kota (DKI) Jakarta. Pilihan pada makna pertama (pemimpin) membawa konsekwensi diharamkannya seorang muslim memilih pemimpin nonmuslim, dalam hal ini Ahok. Sedangkan pilihan pada makna kedua (teman akrab) berdampak tidak dilarang atau dibolehkannya seorang muslim memilih pempimpin non Muslim-dalam hal ini Ahok, karena alQuran hanya melarang orang Islam mengambil "teman akrab", bukan melarang memilih pemimpin non-muslim: Ahok. Dengan demikian, pilihan terjemahan kata "aulia" memiliki konsekwensi politis. Jika maknanya pemimpin: orang Islam tidak boleh memilih Ahok, sebaliknya jika maknanya "teman dekat": Ahok boleh dong dipilih orang Islam, karena toh yang dilarang itu memilih "teman Akrab".

Dapat dibayangkan, bagaimana kerugian politis pada Ahok, jika sebagian besar Islam menerima makna pertama. Orang Islam, tidak peduli Ahok pada sehebat dan sesukses apapun memimpin Jakarta, tidak akan memilih Ahok karena Ia non-muslim. Sebaliknya, Jika orang Islam menerima makna kedua, maka Ahok masih memilki peluang dipilih orang Islam. Dengan demikian perdebatan makna aulia bukan hanya sekedar perbedaan tafsir, tapi juga mengindikasikan perbedaan pandangan dan dukungan politis. Pendukung Ahok, pasti sangat mengingini tafsir kata aulia bukan dimaknai dalam arti pemimpin, karena ini akan mereduksi peluang Ahok untuk dipilih secara luas dari kalangan Islam. Sebaliknya, pendukung Balon Gubernur yang fanatik pada Islam memiliki kepentingan untuk agar tafsir dari kata aulia diarahkan pada pengertian pempimpin karena pada satu sisi akan mereduksi dukungan luas pada Ahok, sementara pada sisi yang lain hal tersebut akan menguntungkan Balon yang muslim, karena ada peluang orang muslim akan memberikan suara kepeda mereka.

Terlepas dari politisasi makna kata aulia sebagaimana terlihat di atas, umat Islam perlu melepaskan diri dari komodifikasi agama karena hanya akan memecah persatuan ummat Islam dan persatuan bangsa. Ada kabut kepentingan yang sangat tebal dalam kontradiksi tafsir surat Almaidah ayat 
51 tersebut. Untuk itu ada beberapa hal yang harus dilakukan agar tidak terjadi lagi politisasi dan komodifikasi agama di masa yang akan datang. Lebih-lebih lagi pada tahun 2019 akan diselenggarakan Pilpres dan Pileg, di antaranya yaitu: (1) harus ada satu lembaga otoritatif dan kredibel untuk memutuskan "perseteruan" tafsir tentang masalah-masalah yang menyangkut ajaran Islam. Jika pada level negara Mahkamah Konstitusi (MK) menjadi penentu akhir dari perseteruan hukum, maka dalam diri umat Islam perlu ada semacam MK yang menjadi pemutus akhir dari aneka perbedaan tafsir tentang ajaran Islam. Di negara Malaysia dan Brunei Darussalam, ototitas tersebut ada pada Majelis Ugama, semacam MUI, pada masing-masing negara tersebut. Sehingga, jika terjadi perbedaan tafsir maka suara resmi dari lembaga tersebutlah yang dipakai. Bukan diserahkan pada kecendrungan subjektif ormas-ormas keagamaan dan masing-masing pribadi sehingga menciptakan ketidak pastian: semua orang punya tafsir sendiri-sendiri. Di Indonesia mestinya otoritas ini diberikan kepada Majelis Ulama Indonesia (MUI). Apalagi anggota MUI terdiri dari pelbagai unsur yang merepresentasi pelbagai mazhab, aliran keagamaan dan ormas di Indonesia. (2) media perlu diatur agar tidak justru menjadi provokator yang memecah belah umat dan bangsa. Media-media perlu didorong kesadarannya untuk memainkan peran sebagai pemersatu bangsa bukan dibiarkan sebebas-bebasnya yang justru mengakibatkan lemahnya sendisendi persatuan bangsa. Untuk itu, Komisi Penyiaran Indonesia (KPI) perlu diberikan peran dan wewenang yang lebih luas untuk membina, mengontrol dan menghukum media jika dianggap merugikan publik dan kepentingan bangsa. (3) pemerintah perlu meningkatkan bargaining-nya pada operator media sosial asing yang beroperasi di Indonesia, seperti facebook, twiter dan lain sebagainya. Populasi penduduk yang besar, lebih dari dua ratus juta bisa menjadi alat penekan media-media sosial asing tersebut agar care juga terhadap kepentingan Indonesia, agar keberadaan persusahaan-persusaan media sosial asing tersebut tidak merugikan Indonesia. Misalnya dengan tidak meng-up date status yang mengandung muatan SARA, atau mendelay 
up-date tersebut sampai informasinya bisa terkonfirmasi kebenarannya, sehingga tidak mengandung unsur fitnah. Jika tidak, pemerintah bisa melarang perusahana-perushaan media sosial beroperasi di Indonesia dan sekaligus membuat media sosial produk Indonesia sendiri seperti yang dilakukan negara-negara besar, seperti China misalnya. Dengan demikian Indonesia bisa melindungi diri dari provokasi media sehingga keuntuhan Indonesia sebagai sebuah bangsa bisa terus terjaga.

\section{Simpulan}

Dari uraian di atas dapat disimpulkan bahwa: (1) Solo Pos berpihak pada Ahok. Ahok di-eksklusi (dihilangkan, diburamkan dari teks naratif) ketika menyangkut informasi negatif dan sebaliknya, di-inklusi (dibuat terang) jika informasi berita positif untuk Ahok. (2) Joglosemar terlihat juga mendukung Ahok. Joglosemar menggunakan teknik eksklusi dan passivasi. Penggunaan kedua teknik ini dilakukan selama memberikan "keuntungan" kepada Ahok. (3) Ada tiga faktor yang mempengaruhi framing, konstruksi dan representasi media yang membuat media terlihat mendukung Ahok, yaitu: Faktor Surakarta sebagai basis partai nasionalis; Faktor Joko Widodo (Jokowi); Faktor pemilik media. Faktor-faktor ini pada akhirnya berdampak pada berita yang terkait dengan kasus penodaan agama yang dilakukan oleh Ahok dimana media cendrung membela Ahok.

\section{Daftar Pustaka}

Abdullah, Irwan, Wening Udasmoro, dan Hasse J. 2009. Dinamika Masyarakat dan Kebudayaan Kontemporer. Yogyakarta: Pustaka Pelajar.

Ajidarma, Seno Gumira. 2016. Jokowi, Sangkuni, Machiavelli. Bandung: Mizan.

Al-Khalwati, Syaik Ahmad bin Muhammad. 1926. Hasyiyah As-Shawi ala al-Jalalain. Mesir: Al-Azhariyah.

Althusser, Louis, 1984. Ideology and Ideological State Aparatuses. London: Verso. . 2014. On Ideology, London. New York: Verso. 
B. J. Boland. 2013. The Struggle of Islam in Modern Indonesia. Springer. Bakri, Syamsul. 2015. Gerakan Komunisme Islam Surakarta 19-14-1942, Jogjakarta: LKiS.

Barker, Chris. 2004. Cultural Studies Theory and Practice. New Delhi: Sage Publication.

Benedict R. O'G. Anderson, Ruth T. McVey. 2009. A Preliminary Analysis of the October 1, 1965 Coup in Indonesia. Jakarta: Equinox Publishing; Reprint edition

Berger, P., \& Luckmann, T. 1966. The Social Construction of Reality: Treatise in the Sociology of Knowledge. New York. New York: Double Day \& Company. Bourdieu, Pierre \& Thompson, John B. 1991. Language and Symbolic Power. Cambridge Mass: Harvard University Press.

Burton, Graeme. 2008. Pengantar Untuk Memahami Media dan Budaya Populer. Yogyakarta. Jalasutra.

Bruinessen, Martin van. 2013. Contemporary Developments in Indonesian Islam: Explaining the "conservative Turn", Singapore: Institute of Southeast Asian Studies.

Cutlip, Scott M. (et.al). 2000. Effective Public Relations. New Jersey: Prentice Hall.

De Rooij, Laurens. 2015. Religious Transformation in Modern Asia: A Transnational Movement. Leiden: BRILL.

Depag RI, Al-Quran dan Terjemahannya. 1989. Semarang: Penerbit Toha Putra.

Fahmi, Muhammad. "Radikalisme Islam dalam Representasi Media di Thailand". Al-Ulum, Vol.16, No. 02, 2016

Fahmi, Muhammad, et.all. "Diskursus Islam Dalam Konstruksi Media", Jurnal Lingua, Vol. 10 No. 2, 2015.

Fairclough, Norman. 1995. Critical Discourse Analysis: The Critical Study of Language. USA: Longman Group Ltd.

Fenton, C.L., and Fenton, M.A. 1940. The Rock Book: New York. Doubleday \& Company, Inc.

Gramsci, Antonio. Prison Notebooks. Columbia: University Press, Vol. 1, 2010. 
Hall, Stuart. 2003. "The Work of Representation" Representation: Cultural Representation and Signifying Practices. London: Sage Publication.

Haryanto, J.T. "Relationship, Transformation and Adaptation of the Traditionalists against Puritanism in Surakarta Indonesia". Analisa Journal of Social Science and Religion, Vol. 22, No. 02, Desember 2015.

Herman, Edward S., \& Chomsky, Noam. 2002. Manufacturing Consent: The Political Economy of the Mass Media, United State of America. Knopf Doubleday Publishing Group.

Intan, Benyamin Fleming. 2006. Public Religion" and the Pancasila-based State of Indonesia: An Ethical and Sociological Analysis. New York: Peter Lang.

Juni Wati, Sri Rizki. 2016. Kepemilikan Media dan Ideologi Pemberitaan. Yogyakarta: Deepublish.

Krishna Sen, David Hill. Politics and the Media in Twenty-First Century Indonesia: Decade of Democracy. Routledge Nov 1, 2010

Khuriyati. T., 2013"Faktor-Faktor Penyebab Penurunan Omzet Penjualan Pada Industri Kerajinan Monel Di Desa Kriyan Kabupaten Jepara". Semarang: UNNES. Semarang.

Leeuwen, Theo van. 2008. Discourse and Practice: New Tools for Critical Analysis. Oxford: Oxford University Press.

Lombard, D. 1996. Nusa Jawa: Silang Budaya. Jakarta: Gramedia.

Mark Woodward. 2010. Java, Indonesia and Islam. London New York: Springer Science \& Business Media.

McQuail, Dennis. 1994. Teori Komunikasi Massa. Jakartal: Erlangga.

Monckton-Smith, Jane. 2012. Murder, Gender and the Media: Narratives of Dangerous Love. New York: Palgrave Macmillan.

Mosco, V., 1998. The Political Economy of Communication: Rethinking and Renewal. University of Winconsin Press.

Mubarok, M. Z. 2008. Genealogi Islam Radikal di Indonesia: Gerakan, Pemikiran, dan Prospek Demokrasi. Jakarta: LP3ES.

Nugroho, H. 1997. "Dekonstruksi Wacana SARA Negara dan Implikasinya Terhadap Kemajemukan Masyarakat Indonesia". Jurnal Ilmu Sosial dan Ilmu Politik, 1(2), 1-12. 
Rahmitasari, Diyah Hayu. 2017. Manajemen Media di Indonesia. Jakarta: Yayasan Pustaka Obor.

Romli, Lili. 2004. Evaluasi pemilihan umum 2004: Analisis Proses dan Hasil Pemilu Legislatif, Jakarta: Pusat Penelitian Politik, Lembaga Ilmu Pengetahuan Indonesia.

Subhan, Imam. 2007. Hiruk Pikuk Wacana Pluralismedi Yogya. Yogayakarta: Impulse \& Penerbit Kanisius.

Sudibyo, Agus. 2001. Politik Media dan Pertarungan Wacana. Yogyakarta: PT LKiS Pelangi Aksara.

Suharto, T. "Gagasan Pendidikan Muhammadiyah dan NU sebagai Potret Pendidikan Islam Moderat di Indonesia". ISLAMICA: Jurnal Studi Keislaman, Vol. 9, No. 1, September 2014.

Suyuti, Muhammad ibn Shihab al-Din; Jalaluddin Muhammad Ahmad al- Muhaili, Tafsir al-Jalalain, 1989, Dar al-Fikr.

Van Dijk, Teun A. 2008. Discourse and Power. New York: Palgrave Macmillan

\section{Internet}

Kompas, 2016, "Ribuan Orang Asal Ciamis Jalan Kaki ke Jakarta ikut Demo Desember". http://www.regional.kompas.com/ $\operatorname{read} / 2016 / 11 / 29 / 15084351 /$ ribuan.orang.a sal.ciamis.jalan.kaki. ke.jakarta.untuk.ikut.demo.2.desember

Republika, 2016, "Aksi Damai 212 Yang Luar Biasa Dahsyat". http://www. republika.co.id/berita/kolom/fokus/16/12/04/ohmzxu257-aksi-damai212-yang-luar-biasa-dahsyat. 